\title{
Effects of granule particle size and lubricant concentration on tablet hardness containing large concentration of polymers
}

\author{
Chauhan Rajani $^{* *}$, Dewangan Devendra Kumar ${ }^{1 *}$, Dwivedi Jaya ${ }^{2}$, Jha Arvind Kumar ${ }^{3}$ \\ ${ }^{1}$ Department of Pharmacy, Banasthali University, Rajasthan,India, ${ }^{2}$ Department of Chemistry, Banasthali University, \\ Rajasthan, India, ${ }^{3}$ Department of Pharmaceutical Sciences, Shri Shankaracharya Institute of Pharmaceutical Sciences, Bhilai, \\ Chhattisgarh, India
}

\begin{abstract}
The objective of this research work is to demonstrate the impact of granule size and lubricant concentration on the hardness of tablets in formulations containing higher concentration of polymers and to resolve the hardness issue during compression process. The work involves optimization of a milling process for size reduction of granules and blending process to achieve tablets of good hardness on compression. To optimize the granule size, different sized co-mill screens were used. The different concentration of lubricant were studied on different sized granules to check the effect on hardness of tablets and to obtained the desired hardness of tablets. Compression of lubricated blend in various concentration was performed using the gravity feeder and force feeder separately to check the impact on the over lubrication effect. This ultimately leads to less hardness tablets. Lubricated blends were evaluated by performing the Bulk Density, Tapped Density, Hausner ratio and compressibility index tests. Tablets were evaluated for the physical characteristics like weight variation, hardness, thickness and dissolution. It has been conclude that on using the optimum granules size and lubricant concentration in formulation, all the downstream problems can be resolved and this in turn helps in compression of tablets and also provides the good hardness to the tablets.
\end{abstract}

Keywords: Tablet hardness/effects. Granule size. Lubricant concentration. Polymer.

\section{INTRODUCTION}

Granule sizes play an important role in obtaining the hardness of tablets. Generally, as granules size increased, tablets were found to show increased weight variation, decreased hardness and increased friability. Whereas in reverse phase, granule size is very small, it leads to issues like sticking due to extra fine particles which enters in between the surface of punch and dies and form a thin film of it on inner surface of die. This finally prevents the compressed tablets to come out of the die i.e. issue of tablet ejection from the die.

Also in other way if the granule size is very small, the actual surface area will be more which in turn requires more lubricant concentration to cover completely. The effects obtained were largely dependent on the type and concentration of lubricant. Tablets containing talc as lubricant, shows decreased disintegration time with

\footnotetext{
*Correspondence: C. Rajani. Department of Pharmacy, Banasthali University, Niwai - Jodhpuriya Road, 304022 - Vanasthali, Rajasthan. E-mail: rajanichauhan_pharma@yahoo.com
}

increased granule size. This represents need of optimum lubricant concentration for the compression of different granule size fractions (Jaiyeobaa, Oladiran, 1983).

The function of a lubricant in the product formulation is to prevent powder from sticking to the punches, dies and other metal components of the tablet press. A lubricant also facilitates the ejection of compacted tablets. Typically, lubricants account for a small percentage of the formula's content. It ranges from $0.25 \%$ to $2 \%$. The most common lubricant in pharmaceutical formulations is magnesium stearate.

There are two common errors when processing lubricants. The first error is neglecting the pre-screening of lubricants to remove the lumpy, over-size particles. The second error is failing to blend the lubricant evenly into the product formulation. The lubricant must be able to contact with metal parts to work correctly. However, it is better to under-blend the lubricant than to over-blend it. Over-blending, will hide the lubricant within the other particles, rendering it useless.

Magnesium stearate, a metallic salt boundary 
lubricant, is probably the most commonly used lubricant for pharmaceutical tableting. It is relatively inexpensive and provides high lubrication.

\section{MATERIAL AND METHODS}

\section{Material}

All the raw materials, Nicergoline (Teva Pharmaceutical Industries), Lactose Monohydrate \{Pharmatose 200M\} (DFE Pharma, Netherlands), Microcrystalline cellulose \{Avicel PH 101\} (FMC Biopolymer, Philadelphia), Povidone $\{$ PVP K-30 $\}$ (BASF Corporation, Germany), Xanthan Gum \{Xanthural 75 \} (CP Kelco, Atalanta USA), Methocel K100 LVCR (Dow Chemicals, Michigan, United States), Lactose Monohydrate \{Flowlac 100$\}$ (Molkerei Meggle Wasserburg Gmbh), Magnesium stearate (Peter Greven, Netherlands) used in the formulation are of $\mathrm{Ph}$. Eur. grade.

The quadro co-mill (Model: U5, Ganson-Quadro), Blender (Model: GMP, Saral), Compression machine 16 station (Model: 102i, Fette compacting, Germany), Compression tooling size of 14X7 mm (Parle Elizabeth tools), Hardness tester (Dr. Schleuniger), Thickness tester (Vernier calliper of Mitutoyo) and Friability apparatus (Electrolab) were used for the processing of blend and compressing into tablets.

\section{Method}

\section{Wet granulation, Drying and Milling process}

The wet granulation method was used for powder blend using high speed mixer granulator with spraying gun and peristaltic pump for binder-water-solution addition. Drying is carried out in Retsch dryer at Research and Development.

The dried granules were taken from the same batch in equal proportion of $2.0 \mathrm{~kg}$ each. Then milling of dried granules were done using the Quadro co-mill with 24C (Condidur hole with hole size of 610 microns), 32R (Round hole with hole size of 813 microns) and $40 \mathrm{G}$ (Grater hole with hole size of 1016 microns) screen. After that blending was done using the double cone blender in R\&D scale batch and multidirectional blender in Pilot scale batch. The milling speed was kept constant. It was $1500 \mathrm{rpm}$, for all the screen size.

\section{Physical properties of powder blend}

\section{Particle size distribution}

Sieve analysis for particle size distribution (Fayed,
Otten, 1997; Hlinak et al., 2006; Shekunov et al., 2006) of milled granules was performed using electromagnetic sieve shaker (Make: Electrolab, Model: EMS-8) with $100 \mathrm{~g}$ material for $5 \mathrm{~min}$ at power 5 starting with the larger sieve on top from $20 \#$ to $120 \#$ sieve. Each sieve along with the retained particles was weighed individually after shaking. The test was completed when the weight on the test sieves did not changed by more than $5 \%$ of the previous weight (Teixeira, 2009).

\section{Bulk density and Tapped density}

Bulk and tapped density of milled granules were performed using the density tester (Make: Electrolab, USP- method 1) using a $250 \mathrm{ml}$ graduated glass cylinder. Approximately $200 \mathrm{ml}$ of powder was carefully filled into the tared glass cylinder ensuring a flat top surface. The maximum bulk volume was noted.

Tapped density was performed at 500, 750 and 1250 taps to get the constant reading. The results are the mean of three replicates (USP, 2007a). Loose bulk density (LBD) and Tapped Bulk density (TBD) have been calculated using as the following equations (Baddam, Bandela, 2013; Carr, 1965).

LBD $=$ Weight of the granules /Untapped Volume of the packing

TBD $=$ Weight of the granules /Tapped Volume of the packing.

Hausner ratio (Hausner , 1967) $=$ Tapped density / Bulk density

Carr's Index $=($ Tapped density - Bulk density $)$ x $100 /$ Tapped density

\section{Blending and lubrication}

Milled granules were blended with extragranular materials for $10 \mathrm{~min}$ at $20 \mathrm{rpm}$ and finally lubricated with magnesium stearate $(0.93 \%$ of total theoretical weight of tablet). It was previously sifted through 60\# sieve in 6 litre capacity double cone blender for $5 \mathrm{~min}$ at $20 \mathrm{rpm}$. The particle size distribution was measured for lubricated granules.

\section{Tablet compression}

\section{Compression using Gravity \& Force Feeder}

The lubricated blend was compressed using both gravity feeder (Table III) and force feeder (Table IV) to check the impact on hardness. Compression done at different turret speed to check the impact of speed on physical parameters of the tablets and the parameters were recorded. Sufficient hardness of tablets around 14-22 kp is required to proceed for coating as next step. 
Compression of blend into tablets with lesser

concentration of lubricant:

Milled granules with $24 \mathrm{C}$ screen were divided into four equal parts of $2.0 \mathrm{~kg}$ each and blended separately with extragranular materials for 10 minutes at $20 \mathrm{rpm}$ and finally it was lubricated. For lubrication, magnesium stearate was used in different concentration. These were $0.23 \%, 0.47 \%, 0.70 \%$ and $0.93 \%$ of total tablet weight (previously sifted through 60\# sieve) in 6 litre capacity double cone blender for 5 minutes at $20 \mathrm{rpm}$. The blend was compressed and physical parameters of the tablets were recorded.

\section{RESULT AND DISCUSSION}

\section{Optimization of milling process}

In initial trials of formulation development, the $40 \mathrm{G}$ screen was selected for milling of dried granules. The granules obtained from the milling through $40 \mathrm{G}$ screen consists of heavier granules along with small portion of fines. Upon pre-lubrication with the extragranular material (comprising 30\% hydrophilic, less dense, fine powder polymers), leads to the segregation of larger granules from the final lubricated blend. This was due to difference in the bulk density of granules and powder during the compression. This was in turn due to vibration in machine and hopper.

To avoid this segregation issue of granules, finer size screen of $32 \mathrm{R}$ and $24 \mathrm{C}$ was selected for milling process as a part of optimization. It was observed that the retains over $40 \#$ sieve is less for $24 \mathrm{C}$ screen granules in comparison to $32 \mathrm{R} \& 40 \mathrm{G}$ screen. It can be clearly seen in the Table III. Also the time required for milling process is less in case of $24 \mathrm{C} \& 40 \mathrm{G}$ screen in comparison with the $32 \mathrm{R}$ screen. (Table II) This in turn depicted the milling process efficiency and cost effectiveness, as the unmilled granules obtained after milling are less. The results are the mean of three replicates (Teixeira, 2009) (Table III).

\section{Powder characterization}

The physical characteristics like Hausner ratio and Carr's compressibility index shows the fair to passable flow of blend.

TABLE I - Unit formula composition

\begin{tabular}{llcccc}
\hline \multirow{2}{*}{ Sr. No. } & \multicolumn{1}{c}{ Ingredients } & \multicolumn{2}{c}{ \%/tab } \\
\cline { 2 - 6 } \multicolumn{1}{c}{ Trial Number } & A & B & C & D \\
\hline Intragranular Materials & & & & \\
\hline 1 & Nicergoline & 6.98 & 6.98 & 6.98 & 6.98 \\
2 & Lactose Monohydrate (Pharmatose 200M) & 7.44 & 7.44 & 7.44 & 7.44 \\
3 & Microcrystalline Cellulose (Avicel 101) & 9.07 & 9.30 & 9.53 & 9.77 \\
4 & PVPK-30 & 8.14 & 8.14 & 8.14 & 8.14 \\
5 & Methocel K100 LVCR & 20.93 & 20.93 & 20.93 & 20.93 \\
6 & Xanthan Gum (Xantural 75) & 6.98 & 6.98 & 6.98 & 6.98 \\
7 & Purified Water & q. s. & q. s. & q. s. & q. s. \\
\hline Extragranular Materials & & & & \\
\hline 8 & Methocel K100 LVCR & 30.23 & 30.23 & 30.23 & 30.23 \\
9 & Lactose Monohydrate (Flowlac 100) & 9.30 & 9.30 & 9.30 & 9.30 \\
10 & Magnesium Stearate & 0.93 & 0.70 & 0.47 & 0.23 \\
\hline
\end{tabular}

TABLE II - Milling parameters

\begin{tabular}{lccc}
\hline Parameters & Co-mill speed $(\mathbf{r p m})$ & Milling time $(\mathbf{m i n})$ & Unmilled portion remained after milling $(\mathrm{g})$ \\
\hline 24C Screen & 1500 & 25 & 97.0 \\
32R Screen & 1500 & 34 & 121.0 \\
40G Screen & 1500 & 22 & 75.0 \\
\hline
\end{tabular}


TABLE III - Particle size distribution data (Cumulative \% weight retained)

\begin{tabular}{lcccccc}
\hline \multirow{2}{*}{ \# Sieve } & \multicolumn{3}{c}{ Milled Granules } & \multicolumn{3}{c}{ Lubricated Granules } \\
\cline { 2 - 7 } & $\mathbf{( 2 4 C ~ s c r e e n )}$ & (32R screen) & (40G screen) & (24C screen) & (32R screen) & (40G screen) \\
\hline 20 & 00.14 & 00.19 & 00.90 & 00.21 & 00.21 & 00.90 \\
40 & 11.24 & 19.69 & 23.76 & 11.02 & 15.56 & 19.40 \\
60 & 17.04 & 29.83 & 36.94 & 14.09 & 40.05 & 28.28 \\
80 & 62.30 & 74.71 & 56.46 & 70.54 & 74.13 & 43.68 \\
100 & 72.98 & 85.84 & 68.70 & 77.94 & 86.01 & 62.54 \\
120 & 76.88 & 88.12 & 77.12 & 80.07 & 91.48 & 76.62 \\
140 & 83.84 & 95.12 & 85.66 & 86.06 & 93.46 & 83.36 \\
Fine collector & 100.48 & 100.41 & 100.16 & 100.66 & 100.17 & 100.08 \\
BD g/mL & $\mathbf{0 0 . 3 8 6}$ & $\mathbf{0 0 . 4 0 4}$ & $\mathbf{0 0 . 4 1 2}$ & $\mathbf{0 0 . 4 1 6}$ & $\mathbf{0 0 . 3 8 7}$ & $\mathbf{0 0 . 4 7 8}$ \\
TD g/mL & $\mathbf{0 0 . 4 8 3}$ & $\mathbf{0 0 . 5 3 1}$ & $\mathbf{0 0 . 5 6 4}$ & $\mathbf{0 0 . 5 4 7}$ & $\mathbf{0 0 . 5 3 1}$ & $\mathbf{0 0 . 6 9 3}$ \\
Carr's Index & $\mathbf{2 0 . 0 0}$ & $\mathbf{2 4 . 0 0}$ & $\mathbf{2 7 . 0 0}$ & $\mathbf{2 4 . 0 0}$ & $\mathbf{2 7 . 1 2}$ & $\mathbf{3 1 . 0 0}$ \\
Hausner Ratio $^{\mathbf{s}}$ & $\mathbf{0 1 . 2 5}$ & $\mathbf{0 1 . 3 2}$ & $\mathbf{0 1 . 3 7}$ & $\mathbf{0 1 . 3 2}$ & $\mathbf{0 1 . 3 7}$ & $\mathbf{0 1 . 4 5}$ \\
\hline
\end{tabular}

*Limit: Fair: 1.19-1.25 (Hausner ratio) \& 16-20 (Carr's index), Passable: 1.26-1.34 (Hausner ratio) \& 21-25 (Carr's index) \& Poor: 1.35-1.45 (Hausner ratio) \& 26-31 (Carr's Index), (General Chapter, 1174 USP, 2007b). \$: Values are mean of three replicate testing.

TABLE IV - Compression data form trial no T1A (using gravity feeder) of 24C screen milled granules

\begin{tabular}{|c|c|c|c|c|c|c|c|c|c|}
\hline $\begin{array}{l}\dot{Z} \\
\dot{n}\end{array}$ & 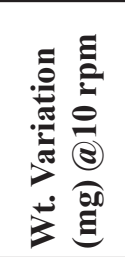 & 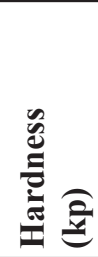 & 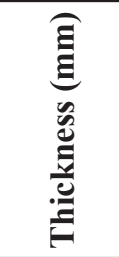 & 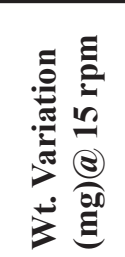 & 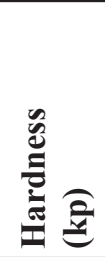 & 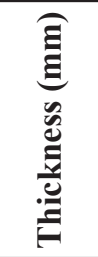 & 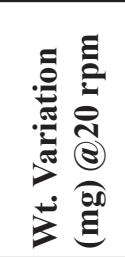 & 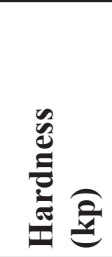 & 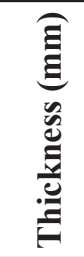 \\
\hline 1 & 436.00 & 20.60 & 05.56 & 436.00 & 16.20 & 05.58 & 436.00 & 16.40 & 05.59 \\
\hline 2 & 433.00 & 21.70 & 05.52 & 433.00 & 17.30 & 05.60 & 433.00 & 16.20 & 05.60 \\
\hline 3 & 435.00 & 22.00 & 05.54 & 432.00 & 16.40 & 05.62 & 432.00 & 15.00 & 05.61 \\
\hline 4 & 430.00 & 20.90 & 05.56 & 436.00 & 17.20 & 05.58 & 434.00 & 15.900 & 05.60 \\
\hline 5 & 433.00 & 21.20 & 05.57 & 432.00 & 16.30 & 05.60 & 436.00 & 16.20 & 05.59 \\
\hline 6 & 437.00 & 20.60 & 05.60 & 436.00 & 15.90 & 05.62 & 433.00 & 16.80 & 05.58 \\
\hline 7 & 433.00 & 19.70 & 05.62 & 433.00 & 16.40 & 05.59 & 429.00 & 15.60 & 05.60 \\
\hline 8 & 429.00 & 20.30 & 05.59 & 434.00 & 16.70 & 05.58 & 433.00 & 15.70 & 05.56 \\
\hline 9 & 433.00 & 20.70 & 05.57 & 436.00 & 16.90 & 05.60 & 430.00 & 16.60 & 05.57 \\
\hline 10 & 436.00 & 20.60 & 05.53 & 434.00 & 17.20 & 05.62 & 431.00 & 16.30 & 05.60 \\
\hline 11 & 432.00 & 21.30 & - & 434.00 & 16.40 & - & 433.00 & 16.70 & - \\
\hline 12 & 434.00 & 20.30 & - & 436.00 & 15.70 & - & 436.00 & 15.90 & - \\
\hline 13 & 433.00 & 20.70 & - & 437.00 & 16.20 & - & 432.00 & 16.30 & - \\
\hline 14 & 433.00 & 21.20 & - & 434.00 & 15.30 & - & 431.00 & 16.40 & - \\
\hline 15 & 436.00 & 21.60 & - & 434.00 & 16.40 & - & 434.00 & 16.30 & - \\
\hline 16 & 430.00 & 20.30 & - & 437.00 & 15.20 & - & 434.00 & 15.90 & - \\
\hline 17 & 432.00 & 20.60 & - & 433.00 & 16.40 & - & 436.00 & 16.30 & - \\
\hline 18 & 436.00 & 20.40 & - & 430.00 & 15.30 & - & 432.00 & 16.40 & - \\
\hline 19 & 437.00 & 21.20 & - & 432.00 & 16.20 & - & 433.00 & 15.70 & - \\
\hline 20 & 433.00 & 21.40 & - & 430.00 & 16.70 & - & 436.00 & 16.30 & - \\
\hline Min & 429.00 & 19.70 & 05.52 & 430.00 & 15.20 & 05.58 & 429.00 & 15.60 & 05.56 \\
\hline Max & 437.00 & 22.00 & 05.620 & 437.00 & 17.30 & 05.62 & 436.00 & 16.80 & 05.61 \\
\hline
\end{tabular}


Bulk density of $24 \mathrm{C}$ passed milled granules indicates that the blend is fluffier in comparison with the granules of 32R \& 40G screen milled granules. Also the Carr's index and Hausner ratio indicates the fair flow of granules with compare to $32 \mathrm{R} \& 40 \mathrm{G}$ screen milled granules, which is having poor flow. (Table III)

\section{Blending and lubrication}

Blending and lubrication time was optimized and fixed to $10 \mathrm{~min}$ and $5 \mathrm{~min}$ respectively. The magnesium stearate concentration's effect on blending and compression has been studied. And it has been found that the higher concentration i.e. $0.93 \%$ of total tablet weight is much higher. This is leading to decrease in hardness of tablets. It has also formed hydrophobic layer over the granules and finally have reduced the compactability between the granules. This ultimately has led to less hardness than the desired. (Table VII)

The study of granules with lubricant concentration of $0.23 \%, 0.47 \%$ and $0.70 \%$ of total tablet weight was performed. It has been observed that the concentration $0.47 \%$ has produced tablets with very good hardness with minimal ejection force and good aesthetic look. The tablets were shining. It indicates the optimum lubrication. Whereas the concentration of $0.23 \%$ has also produced the tablets with good hardness but with the increased ejection force. It has also produced sound during tablet ejection due to inefficient lubrication. (Table I)

Tablets produced with the lubricant concentration of $0.70 \%$ are up to the desired hardness with lesser ejection value. However the hardness obtained was lesser than that of $0.47 \%$ lubricant containing granules. Tablet had good aesthetic value and surface shining.

TABLE V - Compression of data for trial no T1B (using force feeder) of 24C screen milled granules

\begin{tabular}{|c|c|c|c|c|c|c|c|c|c|}
\hline $\begin{array}{l}\dot{z} \\
\dot{\Omega}\end{array}$ & 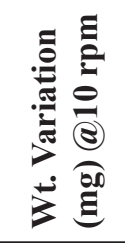 & 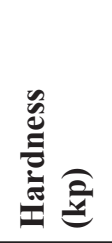 & 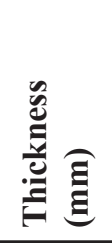 & 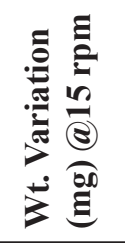 & 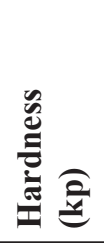 & 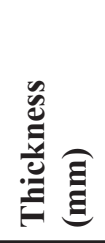 & 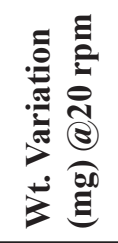 & 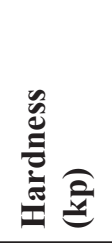 & 总 \\
\hline 1 & 433.00 & 17.30 & 05.58 & 433.00 & 15.60 & 05.57 & 431.00 & 14.60 & 5.54 \\
\hline 2 & 437.00 & 16.30 & 05.60 & 433.00 & 15.90 & 05.60 & 430.00 & 14.30 & 5.56 \\
\hline 3 & 434.00 & 17.20 & 05.62 & 430.00 & 16.20 & 05.61 & 429.00 & 14.90 & 5.57 \\
\hline 4 & 436.00 & 15.20 & 05.61 & 434.00 & 15.90 & 05.57 & 432.00 & 13.70 & 5.60 \\
\hline 5 & 437.00 & 17.70 & 05.65 & 433.00 & 15.70 & 05.56 & 434.00 & 14.60 & 5.61 \\
\hline 6 & 435.00 & 17.80 & 05.54 & 434.00 & 15.60 & 05.58 & 434.00 & 13.70 & 5.65 \\
\hline 7 & 438.00 & 16.60 & 05.56 & 432.00 & 15.20 & 05.58 & 431.00 & 14.70 & 5.60 \\
\hline 8 & 433.00 & 17.50 & 05.57 & 434.00 & 14.40 & 05.60 & 434.00 & 14.70 & 5.58 \\
\hline 9 & 436.00 & 17.90 & 05.60 & 433.00 & 14.70 & 05.62 & 430.00 & 14.40 & 5.54 \\
\hline 10 & 435.00 & 17.40 & 05.61 & 432.00 & 15.60 & 05.61 & 430.00 & 14.70 & 5.56 \\
\hline 11 & 437.00 & 16.80 & 05.57 & 436.00 & 15.30 & 05.61 & 433.00 & 14.70 & 5.57 \\
\hline 12 & 437.00 & 17.00 & 05.56 & 432.00 & 15.70 & 05.57 & 432.00 & 15.00 & 5.56 \\
\hline 13 & 436.00 & 17.40 & 05.58 & 433.00 & 16.00 & 05.56 & 435.00 & 16.20 & 5.58 \\
\hline 14 & 435.00 & 16.90 & 05.57 & 430.00 & 15.30 & 05.58 & 429.00 & 14.20 & 5.57 \\
\hline 15 & 435.00 & 17.20 & 05.61 & 431.00 & 15.60 & 05.57 & 433.00 & 14.60 & 5.61 \\
\hline 16 & 434.00 & 17.70 & 5.65 & 432.00 & 15.60 & 5.61 & 430.00 & 14.40 & 5.54 \\
\hline 17 & 437.00 & 16.50 & 5.60 & 433.00 & 14.90 & 5.60 & 429.00 & 14.40 & 5.59 \\
\hline 18 & 431.00 & 16.90 & 5.58 & 432.00 & 15.70 & 5.58 & 431.00 & 15.20 & 5.53 \\
\hline 19 & 432.00 & 17.20 & 5.54 & 433.00 & 16.30 & 5.54 & 432.00 & 15.60 & 5.56 \\
\hline 20 & 433.00 & 17.80 & 5.57 & 436.00 & 15.90 & 5.56 & 430.00 & 14.60 & 5.57 \\
\hline Min & 431.00 & 15.20 & 5.54 & 430.00 & 14.40 & 5.54 & 429.00 & 13.70 & 5.53 \\
\hline Max & 438.00 & 17.90 & 5.65 & 436.00 & 16.30 & 5.62 & 435.00 & 16.20 & 5.65 \\
\hline
\end{tabular}


TABLE VI - Compression data for trial no T2 and T3 (using force feeder) of 32R \& 40G screen milled granules.

\begin{tabular}{|c|c|c|c|c|c|c|c|c|c|}
\hline \multirow[b]{2}{*}{$\begin{array}{l}\dot{z} \\
\dot{n}\end{array}$} & \multicolumn{3}{|c|}{$\begin{array}{c}\text { Trial No: T2 (with Force Feeder) - } \\
\text { 32R passed granules }\end{array}$} & \multicolumn{6}{|c|}{ Trial No: T3 (with Force Feeder) - 40G passed granules } \\
\hline & 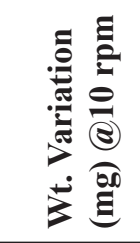 & 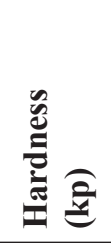 & 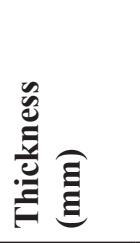 & 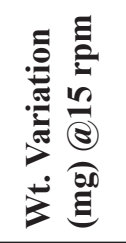 & 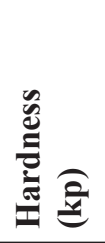 & 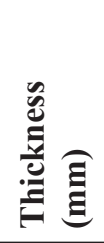 & 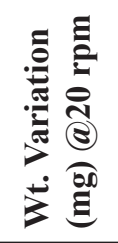 & 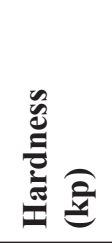 & 总 \\
\hline 1 & 430.00 & 15.40 & 5.64 & 432.00 & 15.50 & 05.69 & 432.00 & 15.60 & 05.60 \\
\hline 2 & 435.00 & 16.60 & 5.68 & 429.00 & 15.40 & 05.66 & 434.00 & 16.00 & 05.58 \\
\hline 3 & 431.00 & 15.90 & 5.67 & 428.00 & 15.40 & 05.67 & 432.00 & 16.00 & 05.56 \\
\hline 4 & 437.00 & 16.50 & 5.70 & 428.00 & 15.70 & 05.66 & 436.00 & 15.90 & 05.61 \\
\hline 5 & 435.00 & 16.40 & 5.67 & 429.00 & 15.30 & 05.69 & 434.00 & 15.50 & 05.56 \\
\hline 6 & 436.00 & 16.100 & 5.64 & 427.00 & 15.40 & 05.67 & 432.00 & 15.90 & 05.58 \\
\hline 7 & 436.00 & 16.50 & 5.66 & 431.00 & 15.90 & 05.64 & 433.00 & 15.70 & 05.60 \\
\hline 8 & 431.00 & 15.20 & 5.64 & 429.00 & 15.10 & 05.68 & 431.00 & 15.70 & 05.61 \\
\hline 9 & 433.00 & 15.50 & 5.67 & 429.00 & 15.40 & 05.64 & 434.00 & 15.90 & 05.58 \\
\hline 10 & 435.00 & 16.30 & 5.64 & 432.00 & 15.80 & 05.66 & 434.00 & 15.40 & 05.56 \\
\hline 11 & 431.00 & 15.20 & - & 427.00 & 15.40 & - & 432.00 & 16.00 & - \\
\hline 12 & 432.00 & 14.90 & - & 430.00 & 15.00 & - & 433.00 & 15.40 & - \\
\hline 13 & 430.00 & 15.60 & - & 430.00 & 15.40 & - & 432.00 & 16.10 & - \\
\hline 14 & 428.00 & 15.70 & - & 429.00 & 15.00 & - & 434.00 & 16.50 & - \\
\hline 15 & 429.00 & 16.20 & - & 432.00 & 15.30 & - & 433.00 & 15.90 & - \\
\hline 16 & 431.00 & 15.90 & - & 426.00 & 15.80 & - & 435.00 & 15.60 & - \\
\hline 17 & 432.00 & 15.50 & - & 429.00 & 14.90 & - & 432.00 & 15.60 & - \\
\hline 18 & 435.00 & 15.30 & - & 430.00 & 15.60 & - & 436.00 & 15.20 & - \\
\hline 19 & 433.00 & 15.80 & - & 429.00 & 15.40 & - & 429.00 & 16.00 & - \\
\hline 20 & 431.00 & 16.00 & - & 429.00 & 15.60 & - & 432.00 & 15.70 & - \\
\hline Min & 428.00 & 14.90 & 5.64 & 426.00 & 14.90 & 5.64 & 429.00 & 15.20 & 5.56 \\
\hline Max & 437.00 & 16.60 & 5.70 & 432.00 & 15.90 & 5.69 & 436.00 & 16.50 & 5.61 \\
\hline
\end{tabular}

Above said trial depicts that the $0.47 \%$ lubricant concentration has been optimal concentration for the formulation and this has been capable of producing the tablets with desired hardness and all physical value. (Table VII).

To counter check the effect of lubricant it had been decided to study the impact of force feeder on tablet hardness. All he blend with different concentration had been compressed using both the gravity feeder and force feeder respectively and it had been observed that the tablets produced using the gravity feeder had the better hardness whereas the tablets produced with force feeder had lesser hardness. Also the hardness is going on reducing with the time in case of blend having the lubricant concentration of $0.93 \%$. Here granules were mixed inside the force feeder area. The feeder speed had been kept at lowest possible speed to prevent the over lubrication however it had not been supported.

It has also been observed that, the tablets observed for 5-10 min of compression have good hardness and this hardness has decreased with time.

\section{CONCLUSION}

Granule size is very much important to obtain the desired hardness of tablets. It has been established from the above experiments and have found that the $24 \mathrm{C}$ milled granules is capable of producing the good tablet hardness in comparison to the $32 \mathrm{R} \& 40 \mathrm{G}$ screen milled granules. Maintained optimized granule size have helped 
TABLE VII - Compression data for trial no T4A, T4B, T4C \& T4D (using force feeder) of 24C screen milled granules

\begin{tabular}{|c|c|c|c|c|c|c|c|c|c|c|c|c|}
\hline \multirow[b]{3}{*}{$\underset{\dot{z}}{\dot{n}}$} & \multicolumn{12}{|c|}{ Trial No: T4 (with Force Feeder) - 24C screen milled granules } \\
\hline & \multicolumn{3}{|c|}{$\begin{array}{c}\text { T4A } \\
(0.23 \% \text { Mg. Stearate) }\end{array}$} & \multicolumn{3}{|c|}{$\begin{array}{c}\text { T4B } \\
(0.47 \% \text { Mg. Stearate }) \\
\end{array}$} & \multicolumn{3}{|c|}{$\begin{array}{c}\text { T4C } \\
(0.70 \% \text { Mg. Stearate) } \\
\end{array}$} & \multicolumn{3}{|c|}{$\begin{array}{c}\text { T4D } \\
(0.93 \% \text { Mg. Stearate }) \\
\end{array}$} \\
\hline & 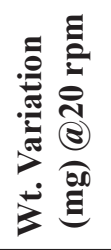 & 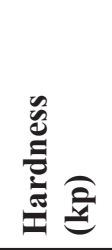 & 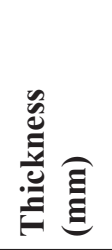 & 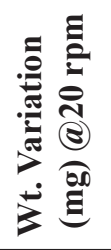 & 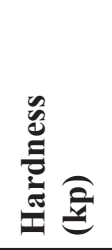 & 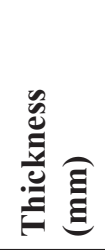 & 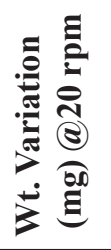 & 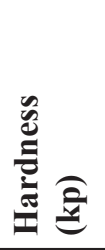 & 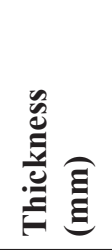 & 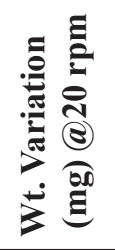 & 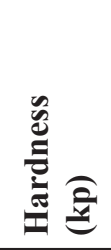 & 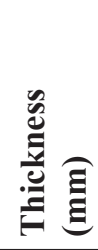 \\
\hline 1 & 428 & 25.60 & 05.49 & 430 & 26.70 & 05.49 & 430 & 21.9 & 05.51 & 426 & 16.10 & 05.50 \\
\hline 2 & 427 & 27.10 & 05.47 & 428 & 26.60 & 05.48 & 428 & 20.1 & 05.50 & 428 & 16.30 & 05.49 \\
\hline 3 & 430 & 25.30 & 05.50 & 426 & 27.00 & 05.49 & 426 & 22.4 & 05.48 & 427 & 16.30 & 05.47 \\
\hline 4 & 431 & 24.90 & 05.49 & 427 & 25.10 & 05.47 & 431 & 21.7 & 05.49 & 430 & 16.10 & 05.48 \\
\hline 5 & 430 & 25.60 & 05.48 & 430 & 24.70 & 05.47 & 430 & 22.5 & 05.47 & 428 & 16.70 & 05.51 \\
\hline 6 & 428 & 24.80 & 05.48 & 428 & 25.30 & 05.48 & 430 & 20.7 & 05.48 & 426 & 16.30 & 05.50 \\
\hline 7 & 426 & 26.10 & 05.49 & 429 & 25.60 & 05.51 & 428 & 21.6 & 05.49 & 428 & 15.90 & 05.51 \\
\hline 8 & 427 & 25.30 & 05.47 & 426 & 23.90 & 05.50 & 426 & 20.9 & 05.48 & 426 & 15.60 & 05.50 \\
\hline 9 & 430 & 25.80 & 05.52 & 430 & 24.70 & 05.48 & 428 & 21.2 & 05.49 & 428 & 15.00 & 05.49 \\
\hline 10 & 428 & 24.90 & 05.51 & 428 & 24.90 & 05.49 & 427 & 21.9 & 05.47 & 427 & 15.30 & 05.48 \\
\hline 11 & 429 & 26.10 & 05.49 & 427 & 25.10 & 05.47 & 430 & 21.0 & 05.50 & 430 & 15.90 & 05.49 \\
\hline 12 & 430 & 26.00 & 05.48 & 430 & 24.70 & 05.48 & 428 & 21.9 & 05.49 & 428 & 15.70 & 05.47 \\
\hline 13 & 428 & 27.10 & 05.51 & 428 & 24.90 & 05.51 & 426 & 20.6 & 05.48 & 426 & 15.60 & 05.48 \\
\hline 14 & 426 & 26.10 & 05.49 & 427 & 25.60 & 05.50 & 428 & 21.4 & 05.48 & 428 & 16.20 & 05.51 \\
\hline 15 & 431 & 26.50 & 05.52 & 431 & 26.00 & 05.49 & 426 & 20.5 & 05.49 & 431 & 15.90 & 05.50 \\
\hline 16 & 430 & 26.10 & 05.48 & 430 & 25.70 & 05.48 & 428 & 21.6 & 05.47 & 433 & 15.70 & 05.49 \\
\hline 17 & 428 & 25.80 & 05.47 & 428 & 25.10 & 05.50 & 431 & 21.6 & 05.50 & 427 & 14.90 & 05.48 \\
\hline 18 & 426 & 25.90 & 05.52 & 431 & 26.10 & 05.51 & 433 & 20.6 & 05.51 & 430 & 15.40 & 05.50 \\
\hline 19 & 430 & 24.90 & 05.51 & 429 & 26.50 & 05.50 & 429 & 21.6 & 05.50 & 431 & 15.80 & 05.49 \\
\hline 20 & 428 & 24.50 & 05.50 & 428 & 25.80 & 05.51 & 427 & 21.2 & 05.52 & 430 & 15.90 & 05.50 \\
\hline Min & 426 & 24.50 & 05.47 & 427 & 23.90 & 05.47 & 426 & 20.1 & 05.47 & 426 & 14.90 & 05.47 \\
\hline Max & 431 & 27.10 & 05.52 & 431 & 27.00 & 05.51 & 433 & 22.5 & 05.52 & 433 & 16.70 & 05.51 \\
\hline Avg & 429 & 25.70 & 05.49 & 429 & 25.50 & 05.49 & 429 & 21.3 & 05.49 & 428 & 15.80 & 05.49 \\
\hline
\end{tabular}

Wt. $=$ weight

in prevention of segregation of granules and also helped in reducing the weight variation and other downstream issues during compression.

The optimum concentration of lubricant in the formulation plays an important role to get the optimum tablets hardness of around $18 \mathrm{kp}$. Due to its hydrophobicity nature, it has formed a layer around the granules. This has prevented the granules to compact-tightly mass. Ultimately this has led to less hard tablets production. So, selection of lubricant concentration for the formulation is very much important for good hardness and aesthetic look is required. This ultimately requires supporting the coating process, as this is next step. This also withstands tablets from attrition and jerk during the coating process for longer time.

Those tablets have not get optimum tablet hardness of about $18 \mathrm{kp}$, lead to abrasion at the tablet surface and finally the tablets produced with rough surface. The optimum concentration of lubricant also affects the tablet hardness when we are using the force feeder for mixing again and again. This leads to over lubrication.

Hence, it has been concluded that on using the optimum granules size and lubricant concentration in formulation, all the downstream problems can be resolved 
and this in turn helps in compression of tablets and also provide the good hardness to the tablets.

\section{ACKNOWLEDGEMENT}

This research was partially supported by Banasthali University- Rajashthan, Shri Shankaracharya Institute of Pharmaceutical Sciences Bhilai and Dr. Reddy's Laboratories Limited.

I am thankful to our colleagues Ram Kumar Sahu, Vellaian Karuppiah who provided expertise that greatly assisted the research, although they may not agree with all of the interpretations provided in this paper.

We are also grateful to Vellaian Karuppiah for assistance with Wet granulation technique, and Ram Kumar Sahu who moderated this paper and in that line improved the manuscript significantly.

We are also immensely grateful to Dr. Rajani Chouhan and Dr. Jaya Dwivedi for their comments on earlier versions of the manuscript, although any errors are our own and should not tarnish the reputations of these esteemed professionals.

\section{REFERENCES}

Baddam MSR, Bandela S. Formulation and evaluation of albendazole sustained release matrix tablets using okra gum. Int J Res Pharm Biomed Sci. 2013;4(4):1344-1353.

Carr RL. Evaluating flow properties of solids. J Chem Eng. 1965;72:69-72.

Fayed ME, Otten L. Handbook of powder science \& technology. $2^{\text {nd }}$ ed. New York: Chapman \& Hall; 1997. 898 p.
Hausner H H. Friction conditions in a mass of metal powder. Int J Powder Metal. 1967;3(4):7-13.

Hlinak AJ, Kuriyan K, Morris KR, Reklaitis GW, Basu PK. Understanding critical material properties for solid dosage form design. J Pharm Innov. 2006;1(1):12-17.

Jaiyeobaa KT, Oladiran OO. The effect of lubricants on the properties of chloroquine phosphate tablets. Drug Dev Ind Pharm.1983;9(1):267-283.

Shekunov BY, Chattopadhyay P, Tong HHY, Chow AHL. Particle size analysis in pharmaceutics: principles, methods and applications. Pharm Res. 2006;24(2):203-227.

Teixeira AZA. Hydroxy propyl cellulose controlled release tablet matrix prepared by wet granulation: effect of powder properties and polymer composition. Braz Arch Biol Technol. 2009;52(1):157-162.

United State Pharmacopoeia. USP. The National Formulary (USP 30-NF 25), The official compendium of standards. Asian edition. Rockville, MD: United State Pharmacopoeial Convention; 2007a. p. 1913-1914.

United States Pharmacopeia. USP. General chapter $n^{\circ} 1174$. USP30 NF 25Pharmacopeia 616. Bulk density and tapped density. Rockville: USP; 2007b.

Received for publication on $12^{\text {th }}$ November 2016 Accepted for publication on $21^{\text {st }}$ March 2017 